\title{
Same-sex sexual behaviour of men in Kenya - implications for HIV prevention, programs, and policy
}

\author{
Scott Geibel \\ Supervisor: Marleen Temmerman \\ Co-supervisor: Stanley Luchters
}

Department of Uro-gynaecology, Ghent University

Public defence: 7 July 2011

From 2004 through 2008, we conducted the first large-scale behavioral surveys of MSM (Men who have Sex with Men) in Kenya; the first being a descriptive study of MSM in Nairobi $[\mathrm{I}, 2]$. Following the success of this initial assessment, a capture-recapture enumeration and an intervention study of male sex workers was conducted in Mombasa.

These studies utilized two different sampling strategies designed to recruit members of hard-to-reach populations (e.g. drug users or sex workers) - snowball and timelocation (also known as time-venue) sampling. Snowball sampling, in which participants randomly recruit peers from their personal networks, was used to reach MSM in Nairobi. Snowball sampling, however, is a non-probability sampling method, and may fail to reach some MSM and produce biased results.

Time-location sampling, in which participants are sampled from a list of contact locations and the times in which they are found at these venues, was used to sample male sex workers in Mombasa. First, we successfully implemented a capture-recapture enumeration of male sex workers who sell sex to men. This entailed conducting two enumerations of male sex workers one week apart, whereupon men counted in only one week or both weeks ("recaptures" or matches) enabled a population estimation derived from capture-recapture calculation. This activity also produced detailed data on locations and times where male sex workers were seeking clients. These data were utilized to produce the time-location sampling frame.

Some of the key findings from these surveys are highlighted in Table 4. Results from these studies firmly established that some MSM in Kenya were engaging in sexual behaviors that put them at risk of HIV infection. In Nairobi, 47 percent of respondents reported multiple male sexual partner activity in the past one month, while 74 percent of male sex workers in Mombasa reported multiple male sexual partners in the past seven days. Men in both studies also reported ever, or currently having, female sexual partners, including some men who reported having female wives. In Mombasa, 29 percent (2006) and 39 percent (2008) of male sex workers reported having a female paying or nonpaying sex partner in the past 30 days.

Self-reported condom use in these studies varied, with as many as 56 percent of MSM in Nairobi reporting consistent condom use in the past 12 months. Only 36 percent of male sex workers in Mombasa, however, reported consistent condom use in the 2006 
baseline survey. A majority of participants in both studies, however, reported using oilbased lubricants. Only 26 percent of MSM in Nairobi and $2 \mathrm{I}$ percent of male sex workers in Mombasa correctly knew that only water-based lubricants should be used with latex condoms, and only $15 \%$ of male sex workers in the 2006 survey had used a water-based lubricant with their last male client. Reported use of oil-based lubricants was significantly associated with ever experiencing condom breakage.

While respondents considered condoms to be available and affordable, water-based lubricants were perceived to be scarce and costly. In Nairobi and Mombasa, water-based lubricants are only available in select supermarkets and pharmacies, where a 50-gram tube of K-Y Jelly costs approximately U.S. \$4.00 (about 320 Kenya Shillings), compared with U.S. \$o.30 (about 25 Kenya Shillings) for a 25 -gram container of petroleum jelly.

\begin{tabular}{|c|c|c|c|}
\hline & Nairobi & $\begin{array}{l}\text { Mombassa } \\
\text { (baseline) }\end{array}$ & $\begin{array}{l}\text { Mombassa } \\
\text { (follow-up) }\end{array}$ \\
\hline \multicolumn{4}{|l|}{ Sample characteristics } \\
\hline Year of survey & 2004 & 2006 & 2008 \\
\hline Target population & $M S M>=I 8$ years & $\begin{array}{l}\text { Male sex workers } \\
>=16 \text { years }\end{array}$ & $\begin{array}{l}\text { Male sex workers } \\
>=16 \text { years }\end{array}$ \\
\hline Sample size & 500 & 425 & 442 \\
\hline Type of study & Descriptive & Intervention & Intervention \\
\hline Sampling methodology & Snowball & Time-location & Time-location \\
\hline Mean age of men in sample & 26 & 27 & 25 \\
\hline \multicolumn{4}{|l|}{ Sexual behaviors } \\
\hline $\begin{array}{l}\text { Consistent condom use } \\
\text { with male partner (\%, time } \\
\text { period) }\end{array}$ & $56 \%$, past 12 months & $36 \%$, past 30 days & $50 \%$, past 30 days \\
\hline $\begin{array}{l}\text { Condom use at last sex with } \\
\text { a male partner }\end{array}$ & $75 \%$ & $58 \%$ & $68 \%$ \\
\hline $\begin{array}{l}\text { Had recent multiple male } \\
\text { partners (time period) }\end{array}$ & $47 \%$, past I month & $74 \%$, past 7 days & $63 \%$, past 7 days \\
\hline $\begin{array}{l}\text { Had recent female sexual } \\
\text { partners (time period) }\end{array}$ & $5 \%$, past I month & $29 \%$, past 30 days & $39 \%$, past 30 days \\
\hline $\begin{array}{l}\text { Received money for sex with } \\
\text { a man (time period) }\end{array}$ & $52 \%$, past 12 months & $87 \%$, past 7 days & $82 \%$, past 7 days \\
\hline \multicolumn{4}{|l|}{$\begin{array}{l}\text { HIV prevalence among MSM } \\
\text { (from other studies) }\end{array}$} \\
\hline $\begin{array}{l}\text { HIV prevalence among com- } \\
\text { parable population }\end{array}$ & $18 \%(n=563)^{\star}$ & \multicolumn{2}{|c|}{$25 \%(n=285)^{\star \star}$} \\
\hline $\begin{array}{l}\text { National HIV prevalence } \\
\text { among all adults age } 15-49\end{array}$ & $9 \%$ & \multicolumn{2}{|c|}{$8 \% \%^{\star \star \star}$} \\
\hline
\end{tabular}

Table 4: Sample characteristics, sexual behaviors, and HIV prevalence of comparable populations 
* Adjusted population-based estimate from respondent-driven sampling; Source: Geibel S, Okal J, Tun W, Sheehy M, Mutua H, Muraguri N, et al. HIVISTI Prevalence and Risk Behavior among Men who have Sex with Men in Nairobi, Kenya. Oral presentation at: University of Nairobi STDIAIDS Collaborative Group Annual Meeting. January 18, 2011, Nairobi, Kenya. ** Unadjusted crude estimate from targeted snowball sampling; Source: Sanders EJ, Graham SM, Okuku HS, van der Elst EM, Muhaari A, Davies A, et al. HIV-1 infection in high risk men who have sex with men in Mombasa, Kenya. AIDS 2007;21:2513-2520.

***National AIDS Control Council and Kenya Ministry of Health. Kenya AIDS Indicator Survey: KAIS 2007, Final Report 2009. National AIDS Control Council and Kenya Ministry of Health. Nairobi; 2009.

Qualitative interviews with male sex workers revealed that the majority of their male sexual partners were Kenyan, and that first sexual experiences with men often took place during adolescence with friends or acquaintances. For some men, though, poverty and coercion also were reported as factors contributing to starting male sex work. Victimization to verbal, physical, and sexual violence was also reported, including by ro percent of respondents in the 2006 male sex worker survey. The qualitative interviews revealed that HIV programs needed to address issues of stigmatization and hatred, which often lead to the violent incidents reported in the study.

These studies did not measure any biological indicators, meaning no testing for HIV or STIs. Findings from other studies in the Nairobi and Mombasa areas, however, help put our findings in perspective with the rest of the Kenyan population. One study of a cohort of MSM (largely male sex workers) conducted in Mtwapa measured a crude HIV prevalence of 25 percent. A recent study among MSM in Nairobi[r] used respondentdriven sampling to estimate HIV prevalence among the total population of MSM in the city area. Crude prevalence among MSM was measured at 25 percent, while statistical adjustment for the respondent-driven sampling reduced the overall estimate to 8 percent. These results from these other studies are shown in Table 4 for comparison and perspective purposes only. HIV prevalence is at least twice as high among MSM than the general population in Kenya ( 9 percent in Nairobi and 8 percent in Mombasa).

These findings highlighted the need for interventions that could safely and effectively target MSM in Kenya. A primary objective of the Mombasa male sex worker study was to determine the feasibility and efficacy of interventions to reduce HIV risk. After implementation of the baseline survey, 40 male sex worker peer educators were trained in HIV prevention and basic counseling skills. Additionally, 20 health-care providers from Mombasa-area hospitals and clinics were trained and sensitized to MSM issues including diagnosis of STIs and HIV counseling. Condoms and water-based lubricants were distributed via a drop-in center and by peer educators.

Significant increases were recorded in correct knowledge of anal HIV transmission (65 percent to 73 percent, $\mathrm{P}<0.01$ ), correct knowledge of use of water-based lubrications with latex condoms ( 20 percent to 40 percent, $\mathrm{P}<0.00 \mathrm{I}$ ), reported condom use with last male client ( 58 percent to 68 percent, $\mathrm{P}<0.0 \mathrm{I}$ ), and consistent condom use with male clients in the past 30 days $\left(3^{6}\right.$ percent to 50 percent, $\left.\mathrm{P}<0.00 \mathrm{I}\right)$. 
Male sex workers reporting increased exposure (range: 0 to $5^{+}$yearly contacts) to peer educators in the Mombasa area were more likely to report consistent condom use (adjusted odds ratio $=I .17, \mathrm{P}<0.0 \mathrm{I})$.

Through careful training and community sensitization, this intervention approach was successful in providing HIV-prevention resources to male sex workers in the highly discriminatory community of Mombasa. This pilot project has since been scaled up by ICRH in the coastal communities of Ukunda, Malindi, and Lamu. 